\title{
Early malnutrition decreases contrast sensitivity to circular concentric gratings
}

\author{
Caroline C. G. Alencar ${ }^{1,2}$ and Natanael A. dos Santos ${ }^{2}$ \\ 1 - Universidade de São Paulo, São Paulo, SP, Brazil \\ 2 - Universidade Federal da Paraíba, João Pessoa, PB, Brazil.
}

\begin{abstract}
Early malnutrition refers to inadequate nutrition during the critical period of nervous system development followed by nutritional recovery, resulting in a short stature according to age but normal weight according to short stature. We measured the effects of early malnutrition on contrast sensitivity (CS) to concentric circular gratings in 18 children of both sexes, aged 8 to 11 years $($ mean $=9.2$ years, standard deviation $=.99$ years $)$. Nine of the children were eutrophic (E group), and nine experienced early malnutrition (EM group) based on state healthcare records and Waterlow's anthropometric parameters. Contrast sensitivity to four spatial frequencies $(.25,1.0,2.0$, and 8.0 cycles per degree [cpd]) was measured using a temporal two-alternative forced-choice psychophysical method with mean luminance of $40.1 \mathrm{~cd} / \mathrm{m}^{2}$. Statistical analyses showed significant differences between groups and a group $\times$ frequency interaction. EM group was significantly less sensitive than the E group to the 8.0 cpd frequency and needed 1.49-times more contrast to detect the gratings. These results suggest that early malnutrition impairs CS to high-spatialfrequency concentric circular gratings in children. Therefore, early malnutrition, which is known to affect primary visual cortical areas, may also affect higher visual cortical areas such as V4 and the inferotemporal cortex. Keywords: early malnutrition; nonCartesian stimuli; contrast sensitivity; extrastriate processing.
\end{abstract}

Received 26 October 2011; received in revised form 27 April 2012; accepted 5 May 2012. Available online 29 June 2012.

\section{Introduction}

Malnutrition is responsible, either directly or indirectly, for the death of more than 6 million children per year (Bryce, 2002; World Health Organization, 2005; Black, Morris, \& Bryce, 2003; Caulfield, Onis, Blossner, \& Black, 2004; United Nations Children's Fund, 2007) and has a profound, nonlethal impact on development. It represents the main environmental factor that contributes to mental retardation and permanent changes in fetal and neonatal development (Galler, 2001; Morgane, Mokler, \& Galler, 2002). Malnutrition contributes as a latent cause to one in two deaths $(53 \%)$ in children $<5$ years of age (World Health Organization, 2005), totaling over 6 million per year

Caroline C. G. Alencar, Laboratório de Neurobiologia Celular, Instituto de Ciências Biomédicas - ICB, Universidade de São Paulo, São Paulo, SP, Brazil. Caroline C. G. Alencar and Natanael A. dos Santos, Laboratório de Percepção, Neurociências e Comportamento, Departamento de Psicologia, Universidade Federal da Paraíba, João Pessoa - PB, Brazil. Correspondence regarding this article should be directed to: Caroline C. G. Alencar, Departamento de Fisiologia e Biofísica, Instituto de Ciências Biomédicas - ICB, Universidade de São Paulo. Av. Prof. Lineu Prestes, 1524 room 239, São Paulo, SP 05508-900, Brazil. Phone: +55 11 30917242. Fax: +55 11 30917426. E-mail: carolalencar@usp.br.
(United Nations Children's Fund, 2007). According to Black et al. (2003), this corresponds to approximately 16,000 children who die each day, one every $5 \mathrm{~s}$.

Proper nutrition is essential for the structural and functional maturation of the central nervous system (Winick, 1975; Morgane et al., 1978; Noback \& Eisenman, 1981; Diaz-Cintra, González-Maciel, Morales, Aguilar, Cintra, \& Prado-Alcalá, 2007). Deficits in protein intake result in a shortage of intake of amino acids necessary for the protein synthesis of structural enzymes, neuropeptides, and neurotransmitters (Galler, Shumsky, \& Morgane, 1996). Moreover, longchain polyunsaturated fatty acids (Morale, Hoffman, Castañeda, Wheaton, Burns, \& Birch, 2005), omega-3 (Uauy, Birch, Birch, Tyson, \& Hoffman, 1990; Uauy, Birch, Birch, Tyson, \& Hoffman, 1992; Uauy, Birch, Birch, Hoffman, \& Tyson, 1993; Uauy, Hoffman, Birch, Birch, Jameson, \& Tyson, 1994; Birch, Birch, Hoffman, \& Uauy, 1992; Hoffman, Birch, Birch, \& Uauy, 1993), and docosahexaenoic, arachidonic, and linoleic acids (Berseth et al., 2011; Scalabrin et al., 2011; Uauy, Hoffman, Mena, Llanos, \& Birch, 2003), among others, are essential for normal human retinal development. Deficits in these in an infant's diet are linked to deficits in vision function.

Both behavioral (Santos, Alencar, \& Dias, 2009; Santos \& Alencar, 2010) and electrophysiological 
(Hoffman et al., 1993; Birch et al., 1992; Uauy et al., 1990; Morale et al., 2005) evidence indicate that inadequate nutrition during development leads to losses in sensitivity to traditional Cartesian sinewave luminance gratings. Does malnutrition affect all of the visual centers in the cortex? Following the lead of recent electrophysiological studies of the primate cortex, we speculated that non-Cartesian grating stimuli may help answer this question.

Prior research indicated that complex stimuli such as non-Cartesian gratings are processed in visual centers beyond V1, such as V2 and V4 (Gallant, Connor, Rakshit, Lewis, \& van Essen, 1996; Merigan, 1996; Wilkinson, James, Wilson, Gati, Menon, \& Goodale, 2000). David et al. (2006) showed that the majority of neurons in V1 are selective for Cartesian gratings, whereas the majority of V4 neurons are selective for non-Cartesian stimuli. Distinct subpopulations that comprise $16-17 \%$ of $\mathrm{V} 4$ cells respond at least twice as strongly to concentric, radial, and hyperbolic stimuli than to sinusoidal gratings, whereas very few cells $(0-8 \%)$ respond best to sinusoidal gratings (Gallant, Braun, \& Van Essen, 1993; Gallant et al., 1996). Cell selectivity decreases for Cartesian gratings and increases for non-Cartesian gratings from V1 to V2 (see Figure 1 in Wilkinson, James, Wilson, Gati, Menon, \& Goodale, 2000).

According to Hegde and Van Essen (2003), however, V2 cells on average respond better to grating stimuli. They are more selective for contour stimuli such as angles, intersections, arcs, and circles. Hegde and Van Essen (2007) found that the percentages of cells that respond better to non-Cartesian gratings than to Cartesian gratings were $65 \%$ for V4 and $61 \%$ for V2.

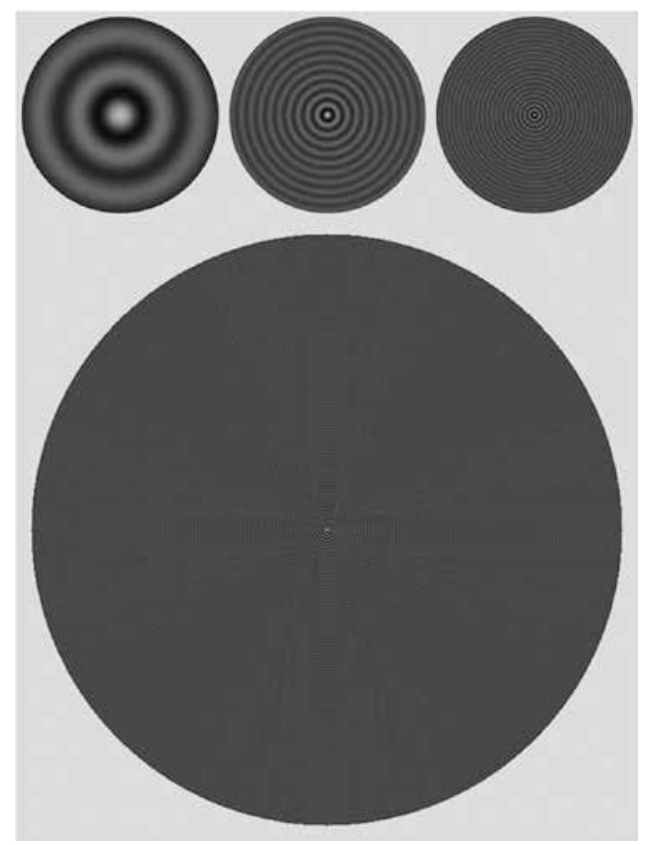

Figure 1. Examples of non-Cartesian visual grating stimuli of .25, 1.0, 2.0 (above from left to right) and 8.0 (below) cycles per degree. The highest SF grating is shown in a larger size due to print reproduction limitations.
Cartesian/non-Cartesian selectivity is apparently not an emergent property of V4 cells (Mahon \& DeValois, 2001). Hegde and Van Essen (2007) also found that some V1 cells with a relatively large receptive field showed a clear preference for complex contours over simple bars and gratings.

Although several studies found differences in the visual system caused by malnutrition using physiological measurements in animals (Cragg, 1872; Warren, \& Bedi, 1982; Gundappa, \& Desiraju, 1988; Bedi, Massey, \& Smart, 1989; Diaz-Cintra, Cintra, Ortega, Kemper, \& Morgane, 1990) and postmortem in humans (BenítezBribiesca, Rosa-Alvarez, \& Mansilla-Olivares, 1999), fewer behavioral studies have investigated these changes in humans.

Based on prior research indicating that nonCartesian gratings are processed with increasing selectivity in visual centers beyond V1, such as V2 and V4 (Gallant et al., 1996; Merigan, 1996; Wilkinson et al., 2000), we sought to extend our prior results that examined the effects of early malnutrition in children using Cartesian sinewave gratings (Santos et al., 2009; Santos \& Alencar, 2010) by examining contrast sensitivity (CS) to non-Cartesian gratings in children who experienced malnutrition.

\section{Material and Methods \\ Participants}

The study included 18 children (10 males, 8 females), 8 to 11 years of age (mean $=9.2$ years, standard deviation $=.99$ years) with normal visual acuity (inclusion criterion). They were tested with directional "E" Rasquin optotype cards (Xenônio, São Paulo, SP, Brazil) and were free of eye diseases or neurological disorders other than those that are malnutrition-related (exclusion criterion). The participants were recruited from the Eradication of Child Labor Program in the Santa Clara community, Castelo Branco, João Pessoa, Paraíba, Brazil.

The children were classified into two groups: $(i)$ nine eutrophic children (E group; height/age $>95 \%$, weight/height $>90 \%$ ) with normal height according to age and normal weight according to height and (ii) nine early malnourished children (EM group; height/ age $<95 \%$, weight $/$ height $>90 \%$ ) with short stature according to age but normal weight according to (short) height and who were malnourished during the critical period of brain development (Morgane et al., 1993) for at least 6 months, from birth to 2 years of age, according to Paraiba state healthcare records. Classification was also based on Waterlow anthropometric parameters (Sigulem, Devincenzi, \& Lessa, 2000), which utilize ratios of weight, height, and age.

Participation of all volunteers considered ethical aspects relevant to research that involves human subjects according to resolution no. 196/96 of the National Health Council (Health Ministry, Brazil). This plan was submitted to and approved by the Ethics Committee 
of the Health Sciences Centre, Universidade Federal da Paraíba. Participation of the children was voluntary and occurred only after written informed consent was provided by their parents or legal guardians.

\section{Visual stimuli and equipment}

The stimuli (Figure 1) were achromatic concentric circular sinewave gratings ( $40.1 \mathrm{~cd} / \mathrm{m}^{2}$ mean luminance) modulated by a cylindrical Bessel profile of zero-order (J0). The spatial modulation eliminated sharp spatial transients at the edge of the gratings and generated a gradual decrease in contrast between the center and edge of the circular grating. At contrast threshold, one can detect the contrast based on the center of the stimulus; however, the contrast threshold was calculated based on the mean contrast of the entire stimulus.

The diameter of the resulting patterns subtended approximately 7.2 degrees at a distance of $150 \mathrm{~cm}$ (i.e., the standardized distance between the monitor and volunteer). The nontest stimulus was gray and contained only average luminance. Test stimuli were concentric, circular, static sinewave gratings (Campbell \& Green, $1965)$ with spatial frequencies of $.25,1.0,2.0$, and 8.0 cycles per degree (cpd). The images (Figure 1) accurately represented the maximum number of cycles visible to the subject. Cycles of 3.6, 7.2, 14.4, and 57.6 were visible to a normal adult at high contrast for .25 , $1.0,2.0$, and $8.0 \mathrm{cpd}$, respectively. Contrast was defined according to Michelson's formula (Michelson, 1891):

$$
C=\frac{(x) \max -L(x) \min }{L(x) \max +L(x) \min }
$$

where $L(x)$ is the luminance at a given point on the sinewave, with $x$ measured radially from the center. $L(x) \max$ and $L(x)$ min are the maximum and minimum luminances of the pattern, respectively. $C$ is the contrast. The spatial average luminance of the grating is given by $1 / 2[\mathrm{~L}(\mathrm{x}) \max +L(x) \min ]$.

Stimuli were presented on a 19 -inch color cathode ray tube video monitor $(1024 \times 768$ resolution, 70 $\mathrm{Hz}$ image update). The stimuli were controlled by a microcomputer through VGA and DVI video connectors. The dynamic range of the contrasts that the monitor could present was expanded more than 64 times by a BITS++ digital video processor (Cambridge Research Systems, Rochester, Kent, England, 2002), resulting in 14 bits per channel or 42 bits per pixel, allowing the presentation of more than 16,384 (or $2^{14}$ ) grayscale levels. This allowed the testing of contrast thresholds while enabling high-contrast resolution. The BITS++ processor was controlled by $\mathrm{C}++$ software developed by our research group. It generated and controlled the stimulus presentation and recorded the observer responses to calculate contrast threshold values.

The monitor was calibrated with LightScan software and an optical photometer (Cambridge Research Systems, Rochester, Kent, England, 2002). The monitor output was gamma-corrected using 48 points from 0 to 255 (gamma $=1.8$ ). The minimum and maximum luminance values of the screen were $.20 \mathrm{~cd} / \mathrm{m}^{2}$ and $80.0 \mathrm{~cd} / \mathrm{m}^{2}$, respectively (average luminance $=40.1 \mathrm{~cd} / \mathrm{m}^{2}$ ), and the background luminance was the minimum luminance itself. The laboratory room was $2.5 \times 2.0 \mathrm{~m}$, with one Philips $20 \mathrm{~W}$ fluorescent lamp. The walls were gray to better control ambient lighting during the experiment.

\section{Procedure}

Observers viewed the stimuli binocularly with natural pupils at a distance of $150 \mathrm{~cm}$. A fixed chair and forehead-chin support were used to control the viewing distance. The visual CS of all of the participants was estimated using a temporal two-alternative forced choice staircase method (Wetherill \& Levitt, 1965). The procedure for measuring the threshold for each frequency consisted of presenting successive pairs of simple stimuli, one of which was the test stimulus that should be identified by the participant (i.e., the first or second stimulus of each pair). The order of the presentation of the stimuli and frequencies was randomized by the software. The criterion used to alternate the contrast during the experimental session was three consecutive hits to reduce contrast by $20 \%$, and one error to increase contrast by the same percentage.

Threshold measurements began with the test stimulus contrast set at a suprathreshold level (contrast $=1$ ). Each time the child gave a correct answer, the contrast was decreased successively until he or she made an error. The software recorded the last perceived contrast value. The contrast was then raised until the child could perceive the stimulus again. In this case, the software recorded the first perceived contrast value. The experimental session ended automatically after the software recorded six staircase contrast values. Each threshold measurement was repeated for each spatial frequency. The contrast threshold calculated for each child was the mean of the 12 contrast values (six at the test and six at the retest).

A stimulus sequence was presented during each experimental session starting with a beep and followed immediately by the presentation of the first stimulus for $2 \mathrm{~s}$. A 1-s interval then elapsed between stimuli, followed by the presentation of the second stimulus for $2 \mathrm{~s}$ and the volunteer's response. All children responded within the 3-s interval. A correct response was followed by another beep. The interval between trials was $3 \mathrm{~s}$, regardless of a correct or incorrect response (or choice). The beeps that indicated the beginning of the stimulus pair presentation and correct choice were different.

All children received the following instructions: "Pairs of circles will appear on the screen, one after the other. One of them will be totally gray, whereas the other will contain light and dark circles (rings) inside it. When the circle with light and dark rings appears first, you must press the left mouse button (button 1); when 
the circle with light and dark rings appears second, you should press the right mouse button (button 2)."

The experiments began only when the experimenter was confident that the participants understood and responded according to the directions. In this context, instructions were repeated in a training and familiarization session with the experimental conditions.

\section{Results}

After each experimental session, the software produced a record sheet with the 12 staircase contrast values from each child, six in the test and six in the retest. Values were grouped according to nutritional status (i.e., E and EM groups). All staircase contrast threshold values were converted into CS values (1/threshold). These values were then plotted into a logarithmic scale for statistical analysis. All 360 staircase contrast values (12 from each child) for each spatial frequency were used to conduct a Tukey Two-Sided Outlier Test. The $13,5,7$, and 20 outlier values for .5, 1.0, 2.0, and 8.0 cpd, respectively, identified by the Tukey test were set to equal the group mean calculated in the absence of the outlier. After the Tukey Outlier Test, the means of the staircase contrast values, converted into CS on a logarithmic scale for each child, were then used to calculate their individual circular CS values.

A one-way analysis of variance (ANOVA) applied to the circular CS revealed significant differences between groups $\left(F[4,13]=7.7, p<.05, \alpha=.97, \eta^{2}=.7\right)$ and a significant interaction $(F[4,13]=1912.9, p<.05, \alpha=$ $\left.1, \eta^{2}=1\right)$. Thus, eutrophic and malnourished children had different CSs $(p<.05)$, and approximately $70 \%$ of this difference was attributable to their nutritional status $\left(\eta^{2}=.7\right)$.

Table 1 shows CSs to $.25,1.0,2.0$, and $8.0 \mathrm{cpd}$ on a logarithmic scale for the E and EM groups. The CSs for $.25,1.0,2.0$, and $8.0 \mathrm{cpd}$ for early malnourished children were 1.07-, 1.03-, 1.03-, and 1.49-fold lower, respectively, than for eutrophic children (Figure 2). The Tukey Honestly Significant Difference post hoc test showed significant differences $\left({ }^{*} p<.05\right)$ only for 8.0

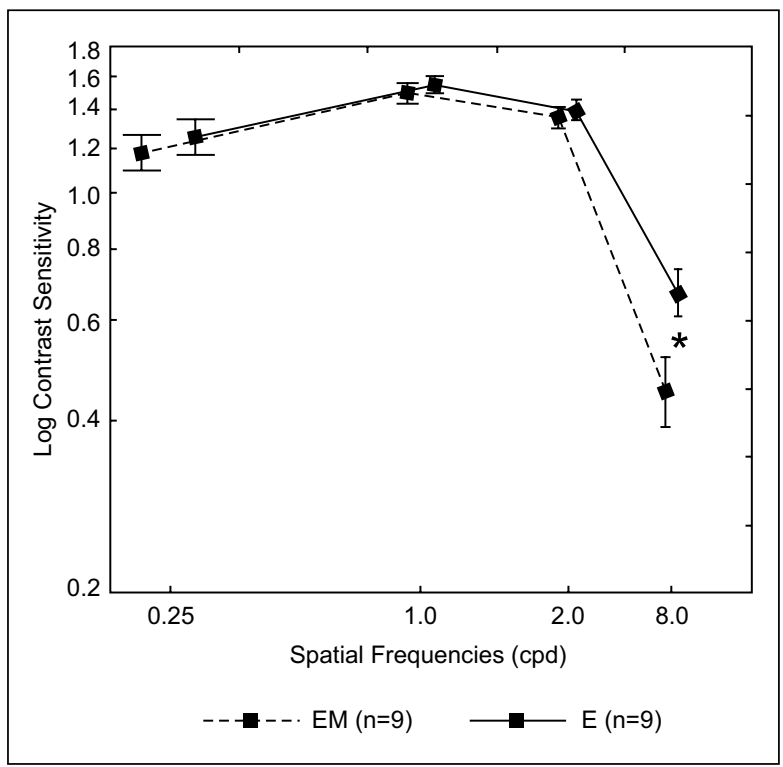

Figure 2. Mean log contrast sensitivity, $\pm 1 \mathrm{SE}$, to concentric circular sinewave gratings of $.25,1.0,2.0$, and 8.0 cycles per degree in children without (E group; $n=9$ ) and with (EM group; $n=9$ ) early malnutrition. Asterisk indicates a significant difference between groups. Vertical bars denote 0.95 confidence intervals.

cpd. For both groups, the CSs for concentric gratings were highest at $1 \mathrm{cpd}$ and lower at both the lower and higher spatial frequencies.

\section{Discussion}

The present study evaluated the effects of early malnutrition on visual circular CS in 8- to 11-year-old children. This type of malnutrition is characterized by nutritional insult at a crucial time in the development of the central nervous system and visual system when malnutrition presents a higher risk, followed by nutritional rehabilitation. In humans, the critical period extends from the third month of pregnancy to 2 years of age (Morgane et al., 1993). A malnourished child has short stature according to age but normal weight according to (short) stature. The central idea of this

Table 1. Valid $n$, mean, median, minimum, maximum, standard deviation (SD), and standard error of the mean (SE) of log contrast sensitivity for the E and EM groups for the $.25,1.0,2.0$, and $8.0 \mathrm{cpd}$ gratings

\begin{tabular}{cccccccc}
\hline E group & Valid $n$ & Mean & Median & Minimum & Maximum & SD & SE \\
\hline .25 & 9 & 1.26 & 1.24 & 1.03 & 1.49 & .14 & .05 \\
1.0 & 9 & 1.55 & 1.57 & 1.36 & 1.67 & .11 & .04 \\
2.0 & 9 & 1.40 & 1.36 & 1.32 & 1.55 & .09 & .03 \\
8.0 & 9 & .67 & .69 & .51 & .83 & .11 & .04 \\
\hline EM group & Valid $n$ & Mean & Median & Minimum & Maximum & SD & SE \\
\hline .25 & 9 & 1.18 & 1.16 & 1.01 & 1.36 & .11 & .04 \\
1.0 & 9 & 1.50 & 1.48 & 1.42 & 1.60 & .06 & .02 \\
2.0 & 9 & 1.36 & 1.35 & 1.28 & 1.47 & .07 & .06 \\
8.0 & 9 & .45 & .45 & .36 & .58 & .02 & .02 \\
\hline
\end{tabular}


study related to predictable responses of the visual system in children who were malnourished for at least 6 months, from birth to 2 years of age.

In previous studies we measured CS to linear gratings in children with acute (Santos et al., 2009) and early (Santos \& Alencar, 2010) malnutrition. We found that acute malnourished children (AM group) with normal height according to age but underweight according to height were 1.34-, 1.27-, 1.50-, and 1.36fold less sensitive to the detection of linear sinewave gratings with spatial frequencies of .25, 1.0, 2.0, and 8.0 cpd, respectively, than children in the E group.

The EM group was 3.3-, 10.9-, and 6.6-fold less sensitive to the frequencies of $.25,1.0$, and $2.0 \mathrm{cpd}$, respectively, but 1.1-fold more sensitive to the frequency of $8.0 \mathrm{cpd}$. This suggests that children in the AM group needed more contrast than the E group to detect all of the spatial frequencies tested, whereas the EM group needed more contrast to detect low and medium spatial frequencies in the test but less contrast to detect the higher frequency tested.

Increased sensitivity to the frequency of 8.0 cpd initially appears contradictory. However, early malnutrition may adversely affect the magnocellular pathway, resulting in losses in the low and mid-low frequencies, but does not affect the parvocellular pathway (i.e., increase in CS with the high frequency). This is possible if one considers that the parvocellular system develops later than the magnocellular system (Wilson, 1988; Norcia, Tyler, \& Hamer, 1990; Suter, Suter, Roessler, Parker, Armstrong, \& Powers, 1994; Ellemberg, Lewis, Liu, \& Maurer, 1999; Adams \& Courage, 2002; Benedek, Benedek, Kéri, \& Janáky, 2003). During the development of the parvocellular system, children may already be nutritionally recovered. This would result in differential reorganization processes that may favor the parvocellular pathway.

The present results showed that early malnutrition decreased CS to concentric circular gratings. Such losses in sensitivity would tend to reduce the visibility of curvilinear edges that form the boundaries of the majority of objects in the natural world, especially under low-lighting, low-contrast conditions.

The statistical results revealed a decrease in CS for the spatial frequency of $8.0 \mathrm{cpd}$ in the EM group. An interaction between early malnutrition and the visual structures that process this spatial frequency may reduce the children's ability to process global information about the shape of the stimulus and fine details. According to Bar (2004), stimulus shape is conveyed by low spatial frequencies, and fine details are conveyed by high spatial frequencies, considering that each frequency range conveys different information about an object.

Both the control and experimental groups presented the same response patterns across spatial frequencies (i.e., peak sensitivity at mid-spatial frequencies [1, $2 \mathrm{cpd}]$ and lower sensitivity at both higher [8 cpd] and lower $[.25 \mathrm{cpd}]$ spatial frequencies). This classic inverted U-shape function has been well established for both static and temporally modulating Cartesian gratings.

The CS reported here for the control group is similar to the CS reported by Santos, França, and Simas (2008) who measured CS to concentric stimuli in 4- to 7 -year-old children and young adults and used the same equipment and procedure as used in the present study. Non-Cartesian Bessel CS is usually found to be lower than Cartesian Linear CS at all ages (see França \& Santos, 2006).

Zana and Cavalcanti (2005) found that the concentric-Bessel CS function has a low-pass shape, peaking at $1.5 \mathrm{cpd}$ or less. One of their main findings was that the Bessel CS function was sharply distinguished from the other curves by its low-pass shape and extremely low sensitivity to high-frequency stimuli.

Kelly (1960) was the first to introduce concentric circular stimuli for use in visual research more than 50 years ago. According to this researcher, nonCartesian stimuli appear to be more natural, considering the symmetrical and circular shape of the retina. Additionally, these circular stimuli provide an easily perceived clear center of fixation (Kelly \& Magnuski, 1975). However, this does not occur with parallel linear gratings. The earliest studies that measured CS to vertical sinewave bars and concentric Bessel function gratings were conducted by Kelly and Magnuski (1975) and Kelly (1982).

Non-Cartesian stimuli may preferentially target cortical visual areas different from the areas targeted by Cartesian gratings. This assumption is based on psychophysical (Wilson, Wilkinson, \& Asaad, 1997; Wilson \& Wilkinson, 1998) and neurophysiological (Heywood, Gadotti, \& Cowey, 1992; Gallant et al., 1996; Merigan, 1996; Wilkinson et al., 2000) research suggesting that Cartesian visual stimuli are decoded in the primary visual cortex, or V1, and circular visual stimuli are decoded in extrastriate visual cortical areas such as area V4 and the inferotemporal cortex.

According to Wilkinson (2000), parallel patterns provided significantly weaker activation in V4 than either concentric or radial patterns. Faces activated V4 at approximately the same level as concentric and radial patterns. This may suggest that the brain regions involved in face perception may show a bias for concentric patterns because of the importance of quasi-circular structure in defining head shape (Wilson, Wilkinson, Lin, \& Castillo, 2000).

According to Wilson et al. (2000), concentric gratings produced roughly half as much activation as faces in the fusiform face area, supporting their hypothesis that the analysis of concentric structure may be an important aspect of face perception. However, V4 cells activated by concentric stimuli may contribute to the analysis of a much wider range of objects. Therefore, future research on both the physiology and psychophysics of intermediate-level form vision should benefit from the use of concentric stimuli rather than simple conventional sinusoidal gratings (Wilkinson et al., 2000). 
Several studies investigated the normal (Bradley \& Freeman, 1982; Adams \& Courage, 2002; Benedek, Benedek, Kéri, \& Janáky, 2003) and abnormal (amblyopia: Montés-Micó \& Ferrer-Blasco, 2001; Down syndrome: Courage, Adams, \& Hall, 1997) childhood development of CS to Cartesian stimuli. However, only a few studies, including the present study, examined the development of CS to non-Cartesian gratings (Santos, França, \& Cruz, 2007; Santos et al., 2008). The present results suggest that early malnutrition, known to affect primary visual cortical areas (Santos \& Alencar, 2010), may affect higher visual cortical areas as well, including V2, V4, and the inferotemporal cortex. To the best of our knowledge, this is the first study to show that early malnutrition decreases CS to non-Cartesian stimuli in later childhood.

In summary, the results of the present study suggest that non-Cartesian stimuli may help evaluate pattern processing in higher visual areas beyond V1 and V2. Additionally, this research also has potential clinical implications. The assessment of non-Cartesian CS may help establish a more nuanced characterization of the effects of malnutrition on the developing visual system and aid in diagnosis, prognosis, and follow-up treatment in children who experienced malnutrition.

\section{Acknowledgements}

The authors wish to thank the State Health Secretariat, João Pessoa, Paraíba, Brazil. Research was supported by FAPESP (no. 2009/53595-6) and CNPq (no. 303822/2010-4, 400837/2010-2, and 478755/2011-2).

\section{References}

Adams, R. J., \& Courage, M. L. (2002). Using a single test to measure human contrast sensitivity from early childhood to maturity. Vision Research, 42, 1205-1210.

Bar, M. (2004). Visual objects in context. Nature Reviews Neuroscience, 5, 617-629.

Bedi, K. S., Massey, R. F., \& Smart, J. L. (1989). Neuronal and synaptic measurements in the visual cortex of adult rats after undernutrition during normal or artificial rearing. Journal of Comparative Neurology, 289, 89-98.

Benedek, G., Benedek, K., Kéri, S., \& Janáky, M. (2003). The scotopic low-frequency spatial contrast sensitivity develops in children between the ages of 5 and 14 years. Neuroscience Letters, 345, 161-164.

Benítez-Bribiesca, L., Rosa-Alvarez, I., \& Mansilla-Olivares, A. (1999). Dendritic spine pathology in infants with severe proteincalorie malnutrition. Pediatrics, 104, e21.

Berseth, C. L., Mitmesser, S. H., Birch, E. E., Khoury, J. C., Bean, J., Harris, C. L., \& Scalabrin, D. M. (2011). Intake of DHA/ARA via breast milk or formula supplementation during infancy can impact the incidence and recurrence of allergic manifestations in young children. European Society of Paediatric Gastroenterology, Hepatology and Nutrition, 2011.

Birch, D. G., Birch, E. E., Hoffman, D. R., \& Uauy, R. D. (1992). Retinal development in very-low birth-weight infants fed diets differing in omega-3 fatty acids. Investigative Ophthalmology and Visual Science, 33, 2365-2376.

Black, R. E., Morris, S. S., \& Bryce, J. (2003). Where and why are 10 million children dying every year? Lancet, 361, 2226-2234.

Bradley, A., \& Freeman, R. D. (1982). Contrast sensitivity in children. Vision Research, 22, 953-959.

Bryce, J. (2002). Better health for poor children: a special report. Geneva: World Health Organization.

Campbell, F. W., \& Green, D. G. (1965). Optical and retinal factors affecting visual resolution. Journal of Physiology, 181, 576-593.
Caulfield, L. E., Onis, M., Blössner, M., \& Black, R. E. (2004). Undernutrition as an underlying cause of child deaths associated with diarrhea, pneumonia, malaria, and measles. American Journal of Clinical Nutrition, 80, 193-198.

Courage, M. L., Adams, R. J., \& Hall, E. J. (1997). Contrast sensitivity in infants and children with Down syndrome. Vision Research, 37 , $1545-1555$.

Cragg, B. G. (1972). The development of cortical synapses during starvation in the rat. Brain, 95, 143-150.

David, S. V., Hayden, B. Y., \& Gallant, J. L. (2006). Spectral receptive field properties explain shape selectivity in area V4. Journal of Neurophysiology, 96, 3492-3505.

Diaz-Cintra, S., Cintra, L., Ortega, A., Kemper, T., \& Morgane, P. J. (1990). Effects of protein deprivation on pyramidal cells of the visual cortex in rats of three age groups. Journal of Comparative Neurology, 292, 117-126.

Diaz-Cintra, S., González-Maciel, A., Morales, M. A., Aguilar, A. Cintra, L., \& Prado-Alcalá, R. A. (2007). Protein malnutrition differentially alters the number of glutamic acid decarboxylase-67 interneurons in dentate gyrus and CA1-3 subfields of the dorsal hippocampus. Experimental Neurology, 208, 47-53.

Ellemberg, D., Lewis, T. L., Liu, C. H., \& Maurer, D. (1999). Development of spatial and temporal vision during childhood. Vision Research, 39, 2325-2333.

França, V. C. R. M., \& Santos, N. A. (2006). The contrast sensitivity to distinct patterns in pre-school children. Paidéia, 16(34), 225-228.

Gallant, J. L., Braun, J., \& Van Essen, D. C. (1993). Selectivity for polar, hyperbolic, and Cartesian gratings in macaque visual cortex. Science, 259, 100-103.

Gallant, J. L., Connor, C. E., Rakshit, S., Lewis, J. W., \& van Essen, D. C. (1996). Neural responses to polar, hyperbolic, and Cartesian gratings in area V4 of the macaque monkey. Journal of Neurophysiology, 76, 2718-2739.

Galler, J. R. (2001). Children and famine: long term effects on behavioral development. Ambulatory Child Health, 7, 85-95.

Galler, J. R., Shumsky, J. S., \& Morgane, P. J. (1996). Malnutrition and brain development. In: W. A. Walker, \& J. B. Watkins (Eds.), Nutrition in pediatrics: Basic science and clinical applications, 2nd edition (pp. 194-210). Philadelphia: B.C. Decker.

Gundappa, G., \& Desiraju, T. (1988). Deviations in brain development of F2 generation on caloric undernutrition and scope of their prevention by rehabilitation: alterations in dendritic spine production and pruning of pyramidal neurons of lower laminate of motor cortex and visual cortex. Brain Research, 456, 205-223.

Hedge, J., \& Van Essen, D. C. (2003). Strategies of shape representation in macaque visual area V2. Visual Neuroscience, 20, 313-328.

Hegde, J., \& Van Essen, D. C. (2007). A comparative study of shape representation in macaque visual areas V2 and V4. Cerebral Cortex, 17, 1100-1116.

Heywood, C. A., Gadotti, A., \& Cowey, A. (1992). Cortical area V4 and its role in the perception of color. Journal of Neuroscience, 12, 4056-4065.

Hoffman, D. R., Birch, E. E., Birch, D. G., \& Uauy, R. D. (1993). Effects of supplementation with omega 3 long-chain polyunsaturated fatty acids on retinal and cortical development in premature infants. American Journal of Clinical Nutrition, 57(5 suppl.), 807S-812S.

Kelly, D. H. (1960). J stimulus patterns for vision research. Journal of the Optical Society of America, 50, 1115-1116.

Kelly, D. H. (1982). Motion and vision: IV. Isotropic and anisotropic spatial response. Journal of the Optical Society of America, 72, 432-439.

Kelly, D. H., \& Magnuski, H. S. (1975). Pattern detection and the twodimensional Fourier transform: Circular targets. Vision Research, $15,911-915$.

Mahon, L. E., \& De Valois, R. L. (2001). Cartesian and non-Cartesian responses in LGN, V1, and V2 cells. Visual Neuroscience, 18, 973-981.

Merigan, W. H. (1996). Basic visual capacities and shape discrimination after lesions of extrastriate area V4 in macaques. Visual Neuroscience, 13, 51-60.

Michelson, A. A. (1891). On the application of interference methods to spectroscopic measurements: I. London, Edinburgh, and Dublin Philosophical Magazine and Journal of Science, Fifth Series, 31, 338-346 and Plate VII.

Montés-Micó, R., \& Ferrer-Blasco, T. (2001). Contrast sensitivity function in children: Normalized notation for the assessment and diagnosis of diseases. Documenta Ophthalmologica, 103, 175-186. 
Morale, S. E., Hoffman, D. R., Castañeda, Y. S., Wheaton, D. H., Burns, R. A., \& Birch, E. E. (2005). Duration of long-chain polyunsaturated fatty acids availability in the diet and visual acuity. Early Human Development, 81, 197-203.

Morgane, P. J., Austin-LaFrance, R. J., Bronzino, J., Tonkiss, J., DíazCintra, S., Cintra, L., Kemper, T., \& Galler, J. R. (1993). Prenatal malnutrition and development of the brain. Neuroscience and Biobehavioral Reviews, 17, 91-128.

Morgane, P. J., Miller, M., Kemper, T., Stern, W., Forbes, W., Hall, T., Bronzino, J., Kissane, J., Hawrylewicz, E., \& Resnick, O. (1978). The effects of protein malnutrition on the developing central nervous system of the rat. Neuroscience and Biobehavioral Reviews, 2, 137-230.

Morgane, P. J., Mokler, D. J., \& Galler, J. R. (2002). Effects of prenatal protein malnutrition on the hippocampal formation. Neuroscience and Biobehavioral Reviews, 26, 471-483.

Noback, C. R., \& Eisenman, L. M. (1981). Some effects of proteincalorie undernutrition on the developing central nervous system of the rat. Anatomical Record, 201, 67-73.

Norcia, A. M., Tyler, C. W., \& Hamer, R. D. (1990). Development of contrast sensitivity in the human infant. Vision Research, 30, 1475-1486.

Santos, N. A., \& Alencar, C. C. G. (2010). Early malnutrition diffusely affects children contrast sensitivity to sine-wave gratings of different spatial frequencies. Nutritional Neuroscience, 13, 189-194.

Santos, N. A., Alencar, C. C. G., \& Dias, Y. H. N. (2009). Contrast sensitivity function of sinewave gratings in children with acute malnutrition. Psychology \& Neuroscience, 2, 99-103.

Santos, N. A., França, V., \& Simas, M. L. B. (2008). Radial frequency contrast sensitivity in children of 4 to 7 years old and adults. Psicologia: Reflexão e Crítica, 21, 28-32.

Santos, N. A., França, V. C. R. M., \& Cruz, E. D. N. (2007). Percepção de padrões concêntricos em crianças de 8 a 13 anos. Paidéia, 37, 253-264.

Scalabrin, D. M., Mitmesser, S. H., Birch, E. E., Khoury, J. C., Bean, J., Harris, C. L., \& Berseth, C. L. (2011). Lower incidence and less recurrence of allergic manifestations is observed in children who received DHA/ARA in infancy via breast milk or supplemented formula. European Academy of Allergy and Clinical Immunology, in press.

Sigulem, D. M., Devincenzi, M. U., \& Lessa, A. C. (2000). Diagnóstico do Estado Nutricional da Criança e do Adolescente. Jornal de Pediatria, 76(3), 275-284.

Suter, P. S., Suter, S., Roessler, J. S., Parker, K. L., Armstrong, C. A., $\&$ Powers, J. C. (1994). Spatial-frequency-tuned channels in early infancy: VEP evidence. Vision Research, 34, 737-745.

Uauy, R., Birch, D., Birch, E., Hoffman, D., \& Tyson, J. (1993). Effect of dietary essential omega-3 fatty acids on retinal and brain development in preterm infants. In: Essential Fatty Acids and Eicosanoids, (A. Sinclair and R. Gibson, eds.) American Oil Chemists' Society, Champaign, IL, 197-202.

Uauy, R., Hoffman, D. R., Birch, E. E., Birch, D. G., Jameson, D. M., \& Tyson, J. (1994). Safety and efficacy of omega-3 fatty acids in the nutrition of very low birth weight infants: Soy oil and marine oil supplementation of formula. Journal of Pediatrics, $124,612-620$.

Uauy, R., Hoffman, D. R., Mena, P., Llanos, A., \& Birch, E. E. (2003). Term infant studies of DHA and ARA supplementation on neurodevelopment: Results of randomized controlled trials. Journal of Pediatrics, 143(4 suppl.), S17-S25.

Uauy, R. D., Birch, D., Birch, E., Tyson, J., \& Hoffman, D. (1992). Are omega-3 fatty acids required for normal eye and brain development of the very low birthweight infant? In: Recent Advances in Infant Feeding, (B. Koletzko, ed.) Verlag, New York. 13-21.

Uauy, R. D., Birch, D. G., Birch, E. E., Tyson, J. E., \& Hoffman, D. R. (1990). Effect of dietary omega-3 fatty acids on retinal function of very-low-birthweight neonates. Pediatric Research, 28, 485-492.

United Nations Children's Fund (2007). Progress for children: A world fit for children. Statistical Review, 6, 1-68.

Warren, M. A., \& Bedi, K. S. (1982). Synapse-to-neuron ratios in the visual cortex of adult rats undernourished from about birth until 100 days of age. Journal of Comparative Neurology, 210, 59-64.

Wetherill, G. B., \& Levitt H. (1965). Sequential estimation of points on a psychometric function. The British Journal of Mathematical and Statistical Psychology, 18, 1-10.

Wilkinson, F., James, T. W., Wilson, H. R., Gati, J. S., Menon, R. S., \& Goodale, M. A. (2000). An fMRI study of the selective activation of human extrastriate form vision areas by radial and concentric gratings. Current Biology, 10, 1455-1458.

Wilson, H. R. (1988) Development of spatiotemporal mechanisms in infant vision. Vision Research, 28, 611-628.

Wilson, H. R., Wilkinson, F., \& Asaad, W. (1997). Concentric orientation summation in human form vision. Vision Research, 37, 2325-2330.

Wilson, H. R., \& Wilkinson, F. (1998). Detection of global structure in Glass patterns: Implications for form vision. Vision Research, 38, 2933-2947.

Wilson, H. R., Wilkinson, F., Lin, L. M., \& Castillo, M. (2000). Perception of head orientation. Vision Research, 40, 459-472.

Winick, M. (1975). Effects of malnutrition on the maturing central nervous system. Advances in Neurology, 13, 193-246.

World Health Organization (2005). Challenges: World health report. Geneva: World Health Organization.

Zana, Y., \& Cavalcanti, A. C. (2005). Contrast sensitivity functions to stimuli defined in Cartesian, polar and hyperbolic coordinates. Spatial Vision, 18, 85-98. 
